\title{
СТУДЕНТ СЕГОДНЯ - СПЕЦИАЛИСТ ЗАВТРА (К ВОПРОСУ ОБ ЭФФЕКТИВНОСТИ ИДЕЙНО-ВОСПИТАТЕЛЬНОЙ РАБОТЫ КОМСОМОЛА В ВУЗЕ)
}

\author{
О. И. Карпухин \\ Московский гуманитарный университет
}

Аннотация: В статье приводятся данные социологических исследований 1970-х годов, проведенных с участием автора статьи. Они были посвящены изучению вопросов социально-профессиональной ориентации советской молодежи.

Ключевые слова: качество трудовой жизни; социально-трудовые отношения; социальная политика; социальное партнерство

\section{STUDENT TODAY, PROFESSIONAL TOMORROW (ON THE ISSUE OF THE EFFICIENCY OF KOMSOMOL'S IDEOLOGICAL AND EDUCATIONAL ACTIVITY AT A UNIVERSITY)}

\author{
O. I. Karpukhin \\ Moscow University for the Humanities
}

Abstract: The paper presents the data of the 1970s surveys carried out with the participation of the author. They were dedicated to the issues of social and professional orientation of the Soviet youth.

Keywords: youth; survey; Komsomol; history of the USSR; All-Union Leninist Young Communist League; sociological research

Благодаря комсомолу и волею судеб в середине 1970-х годов мы были приглашены в Москву из разных городов и весей на работу в отдел студенческой молодежи ЦК ВЛКСМ. За плечами каждого из нас был немалый опыт профессиональной и комсомольской работы. Но объединяло нас, пожалуй, одно - молодость, уверенность в своих силах и азарт, а самое главное преданность высшей школе и науке. Кстати, некоторые из нас уже испытали на себе искус научной работы, став кандидатами наук. И, конечно же, мы гордились причастностью к самому передовому, на наш взгляд, отряду Ленинского комсомола - студенчеству, чьи славные дела так ярко прозвучали в речи Генерального секретаря ЦК КПСС Л. И. Брежнева на Всесоюзном слете студентов. Не на словах, а на деле многие из нас прошли школу студенческих отрядов, целины, агитпоходов по местам боевой славы. 
Придя из науки и вузов, мы старались привнести в работу комитетов комсомола творческий, исследовательский подход. Ученые обществоведы, социологи ведущих кафедр страны охотно помогали нам в этом. Как не вспомнить с благодарностью тот неоценимый вклад в проведение Всесоюзных конкурсов лауреатов студенческих работ по общественным наукам, истории ВЛКСМ и Международного молодежного движения, который внесли ученые Высшей комсомольской школы, Московского, Ленинградского и Воронежского университетов. Когда же внедрялась такая комплексная система идейно-воспитательной работы, как общественно-политическая практика студентов, была проведена целая серия всесоюзных конференций и семинаров по ее внедрению в вузах страны, прежде чем Минвуз СССР и ЦК ВЛКСМ приняли типовое положение.

Каким должен быть профиль современного специалиста? - вот лейтмотив дискуссий, свидетелем и участником которых мы были в то время. Разгар дискуссий пришелся на первую половину 1970-х годов. Высказывались разные, нередко взаимоисключающие точки зрения. Сторонники организации учебного процесса по принципу узкого профилирования обосновывали свою точку зрения ссылками на углубляющуюся дифференциацию науки, увеличение объема знаний, невозможность объять необъятное». Их оппоненты из противоположного лагеря, наоборот, утверждали, что в условиях динамизма научных знаний специалисты широкого профиля, обладающие фундаментальной общенаучной подготовкой, функционально мобильные, способные быстро адаптироваться к меняющейся научно-технической обстановке, необходимы производству как «воздух необходим всему живому».

Социологические исследования 1970-х годов зафиксировали заметный сдвиг социально-профессиональной ориентации молодежи. Если по данным исследований в середине 1960-х годов 90\% выпускников общеобразовательных школ намерены были поступать в высшие учебные заведения и рассматривали эту перспективу как единственно желательную из-за существования социальных лифтов, то исследование, проведенное Институтом социологических исследований АН СССР в 1973-1975 годах, выявили, что на высшее образование уже ориентировано менее половины выпускников школ. Вместе с тем, почти все опрошенные высказали желание получить до начала деятельности профессиональное образование. Не удивительно, что увеличивалось количество узко - профильных вузов, техникумов и профессиональных училищ. И в этом была немалая заслуга ленинского комсомола.

По инициативе комсомола во многих вузах страны создавались подготовительные отделения в целях выравнивания социально-классовой структуры студенческой молодежи, широкому вовлечению в ее ряды луч- 
Научные труды Московского гуманитарного университета 2018 № 6

ших представителей рабочей, колхозной и армейской молодежи.

В конце 1970-х годов отдел студенческой молодежи ЦК ВЛКСМ стал больше внимания уделять анализу эффективности деятельности комитетов комсомола в вузах в связке «школа - вуз - производство». Впервые для этой цели при подготовке вопроса на бюро ЦК ВЛКСМ о работе комитета комсомола Воронежского университета по коммунистическому воспитанию студенчества было проведено комплексное социологическое исследование среди студентов старших курсов и молодых специалистов, выпускников этого университета. Опрос студентов и молодых специалистов выявил как сильные, так и слабые стороны работы комсомола. Все это помогло выработать конструктивные рекомендации по усилению работы комитетов комсомола на местах. В частности, было выявлено, что в жизнедеятельности студентов большую роль играют перспективные моменты, определяемые подготовкой к выполнению будущих социально-профессиональных функций.

Окончание учебы в вузе, получение диплома для каждого выпускника означало получение профессии и нового социального положения, вхождение в состав интеллигенции, работников высококвалифицированного умственного труда. На завершающей стадии обучения перед студентами актуально вставали вопросы определения места работы и жительства, изменения привычных форм режима жизнедеятельности, устройства своего быта в новых условиях. К тому же у многих выпускников окончание вуза часто совпадало и с изменением и своего семейного положения - вступлением в брак. Все это требовало от них не только полученных в вузе знаний, но и характера, тех гражданских качеств, которые должны стать достоянием личности молодого специалиста. Как показало исследование, на осознание этих перспективных моментов оказывали влияние многие факторы реального жизненного процесса: семейное воспитание, круг друзей, средство массовой информации и другое. У студентов этот процесс развивался под решающим воздействием учебно-познавательной, научной, общественно-политической деятельности, в ходе которой у них формировалось профессиональное сознание, а оно неизбежно накладывало свой отпечаток на процесс жизненного планирования.

В социологической литературе жизненные планы молодежи рассматриваются как одно из проявлений общественного сознания, а их формирование социально-обусловленный процесс. В условиях разных общественных систем он неизбежно несет на себе печать объективно существующих различий в экономике, в социальной структуре, в политике, в идеологии. В современном капиталистическом обществе, как об этом писали американские социологи Р. Клоуварт, Р. Оулин, Ф. Мейер, желания и планы аме- 
риканской молодежи базируются в основном на ценностях индивидуализма, которыми буквально пропитан американский образ жизни. Основными ориентирами в жизненных планах выступают идеалы потребительства. Профессиональные знания, способности личности ценятся при этом как оружие достижения власти и богатства. На наш взгляд, эти процессы характерны и для современного российского общества.

В 1970-1980-е годы, как показало наше социологическое исследование, содержание, направленность жизненных устремлений и планов воронежского студенчества формировалось при решающем воздействии социалистических общественных отношений. Велика при этом была роль организованной системы обучения и воспитания, которую осуществлял комсомол вместе с профессорско-преподавательским коллективом. И в задачу входило «поведение» общественных потребностей к жизненным планам, согласование объективных и субъективных сторон в процессе подготовки и включение молодежи в самостоятельную жизнь. Анализ жизненных планов, выражавших деятельное отношение воронежских студентов к миру социальных ценностей, условиям самореализации в качестве специалистов и зрелых граждан социалистического общества, свидетельствовало о безусловном преобладании в их духовной структуре социально значимых ориентиров. Для абсолютного большинства студентов выпускников первостепенное значение в жизни представляли ценности, связанные с возможностью заниматься любым интересным делом, проявлять свои творческие способности, быть полезным обществу, людям, реализация этих возможностей молодыми людьми не мыслится иначе как посредством и при помощи активной трудовой и общественной деятельности. На вопрос анкеты: «Если бы вы были абсолютно свободны в принятии жизненных решений, что бы вы предпочли?» - ответили:

Жизнь в труде - 84,6\%;

Жизнь без труда - 1,2\%;

Затруднились определить - $14,2 \%$

Абсолютное большинство студентов, таким образом, в предложенной им ситуации «абсолютной», то есть не регламентированной никакими общественными нормами и предписаниями, свободы предпочли «жизнь в труде». Это свидетельствовало о том, что для выпускников воронежского университета труд и трудовая жизнь осознавались не только как необходимость (труд при социализме есть право и обязанность граждан), но и как потребность, как одна из высших социальных ценностей, как естественный и предпочитаемый способ жизненной самореализации человека.

Представляется естественным при этом, что большинство молодых людей было озабочено также устройством личной жизни. Проблема соб- 
Научные труды Московского гуманитарного университета 2018 № 6

ственной семьи, ее благополучие существенное значение имело для 91,2\% выпускников.

Таким образом, можно говорить о двух взаимоувязанных линиях жизненной самореализации будущих специалистов - профессиональных и личных. Первое - осознается студентами как приоритетное, поскольку обусловливает во многих отношениях решение личных проблем, как материального, так и духовного порядка. В шкале ценностей в связи с предстоящей профессиональной деятельностью на первое место выпускники ставили «возможность творческой работы» $-4,4$ балла из пяти. Потом идут: «самосовершенствование» - 4,2 балла. Затем идут: «комфортные условия жизни» - 4,3 балла, потом: «профессиональный рост» - 4 балла, «польза общества, людям» - 4 балла, «материальная обеспеченность» $-3,8$ балла, «продвижение по службе» - 3,5 балла, «профессиональный авторитет, известность» - 3, 3 балла.

Думается, что содержание ценностных ориентаций в целом не противоречило личности социалистического типа. Увлеченный творческий труд на благо общества, стремление к совершенствованию через самореализацию в многогранной общественной деятельности и получение от общества достаточных для нормальной жизни человека материальных благ - все это в высшей степени отвечало основным принципам организации жизни людей в условиях социализма. Содержание ценностных ориентаций свидетельствовало таким образом о коллективистской направленности выпускников ВГУ, о высоком уровне их нравственного развития. Делая такой вывод, мы, разумеется, отдавали себе отчет в том, что степень осознания нравственных норм и идеалов не всегда находило адекватное отражение в устойчивости моральных качеств личности, в ее убежденности, побуждающей всегда при любых обстоятельствах поступать в соответствии с требованиями моральных норм.

Таким образом, эффективность вклада выпускника вуза в систему общественного производства, науки, культуры и образования определялась не только солидностью багажа его профессиональных знаний и умений, но и прежде всего уровнем сформированности его как личности, цельности его характера, четкой определенности его жизненных установок. Правда, в нашем исследовании возникла и проблемная ситуация. Дело в том, что в явном несоответствии с оценкой своей убежденности была оценка студентами своей общественной активности. Почти у трети опрошенных она была представлена по их самооценке как «низкая». Отдадим должное критическому отношению выпускников. Следует лишь отметить, что оценивали они общественную активность не в субъективном плане, не как свое желание и стремление участвовать в общественной работе, а реализацию этих 
стремлений в конкретных условиях того или иного учебного коллектива. К сожалению, многим студентам за годы учебы так и не удавалось попробовать свои силы в какой-либо общественно значимой (не учебной) деятельности.

По нашим данным, до одной трети студентов на отдельных факультетах не принимало участия в общественной работе, не имело поручений. Еще сложнее обстояло дело с лекционно-пропагандистской практикой. Сама организация учебно-воспитательного процесса не давала студентам достаточного простора для апробации их организаторских способностей и умений, и это тоже отражено в оценках выпускников.

Вместе с тем при всей противоречивости полученных оценок нельзя не обратить внимания на то, что направленность жизненных ориентаций выпускников в целом, подтверждает неформально декларируемую убежденность, а внутренне осознанную приверженность социалистическим ценностям.

Тем не менее, наше исследование показало, что установка на общественную работу у студентов ВГУ была неразрывно связана с теми ценностными ориентациями, которые имелись у них в связи с участием в ней. Так, студенты считали, что хорошо организованная общественная деятельность позитивно сказывается на процессе профессионального и гражданского становления специалиста. При этом высказали мнение, что эта работа:

Делает жизнь более интересной и социально значимой $-57,9 \%$,

Развивает организаторские способности, формирует необходимые навыки - 63,9\%,

Способствует более успешной учебе $-28,5 \%$,

Расширяет круг знакомых, друзей $-70,1 \%$,

Позволяет лучше подготовиться к практической деятельности по окончании вуза - 66,8\%,

Способствует завоеванию авторитета, уважения со стороны студентов, преподавателей $-51,5 \%$,

Дает некоторые преимущества при распределении на работу, в получении места в общежитии и др. - 34,3\%,

Приносит моральное удовлетворение - 71,2\%.

Выявлена довольно четкая связь между уровнем ценностных ориентаций, их характером и направленностью отношения студентов к выполнению общественных поручений. Так, среди студентов, имеющих высокий уровень ценностных ориентаций, 87,2\% опрошенных выполняют поручения с интересом, инициативно. Среди тех, кто имеет средний уровень, 50,7\% обнаруживают инициативное отношение к выполнению поручений. А среди имеющих низкий уровень - лишь 17,6\%. В этой связи нельзя не подчеркнуть, что только в процессе творческого инициативного участия молодых людей 
Научные труды Московского гуманитарного университета 2018 № 6

в общественной работе, они наиболее глубоко осознавали ее социальную и личностную значимость.

Особо стоял вопрос о социальном лице - активе, о лидерах, комсомольских вожаках. К сожалению, в ходе исследования нередко обнаруживалось фактическое несовпадение формального и неформального лидерства в группах. А также и на уровне курса, факультета, вуза. Прежде всего бросалось в глаза несоответствие высоких требований, предъявляемых официальным лидерам, и реальных показателей их учебной, научной активности. Не парадоксально ли, что среди «титулованных» было немало просто слабоуспевающих студентов, кочующих от семестра к семестру в сопровождении неизменной «свиты» неудовлетворительных и посредственных оценок.

Иногда, опять же волею случая, в лидеры попадали те студенты, о которых можно сказать «спокойные», «воды не замутят». В студенческой же среде острее ощущалась потребность в людях увлеченных, нестандартных, творческих, духовно приподнятых, способных увлекать и вести за собой студенческую массу, способность и стремление жить, обгоняя время, организовывать уже сегодня жизнь при ориентации на завтрашний день - все это так необходимо современному специалисту. Сформироваться эти качества могли лишь в живой атмосфере настоящей инициативной интересной и ответственной комсомольской работе. Об этом свидетельствуют примеры из жизни комсомольской организации ВГУ. То, что помогало 8-тысячам обучающимся в ВГУ из года в год подниматься на новый виток академических и общественных дел, проверяющие называли «покурсовой динамикой развития студента» - процесс предусмотренный и теоретически спланированный в программе коммунистического воспитания студентов на весь период обучения. Суть этой программы кратко можно сформулировать так: ускоренное развитие личности современного специалиста.

Предусмотрев согласованность всех звеньев воспитательного процесса с учетом его направленности на достижение конкретно поставленных целей, программа была направлена против анархии и рутины отдельных кафедр, деканатов, активистов, ранее руководствовавшихся лишь сугубо ведомственными интересами. Добились того, что кафедральные планы воспитательной работы стали конкретными аналогами общевузовской программы, ориентирующей на комплексный подход к воспитанию. Как это осуществлялось на деле, видно хотя бы на таком примере.

У студентов экономического факультета практика на предприятиях Коминтерновского района. И пока будущие специалисты вникали в конкретную экономику, университетские социологи исследовали их взаимоотношения с трудовыми коллективами. Факультетская кафедра, естественно, заботилась, чтобы студенты приобрели как можно больше профессиональ- 
ных навыков. А кафедра педагогики изучала взаимное воспитательное влияние студенческого и трудового коллективов.

Факультетское бюро ВЛКСМ предложило студентам: помогите рабочим принять реальные обоснованные экономические планы. И после такой компетентной помощи будущих специалистов на предприятии заметно поубавилось надуманных обязательств.

Назовем еще одно доброе дело, сделанное студентами: двух молодых рабочих экскаваторного завода, пятикурсники, между делом подготовили для поступления в университет. Да и сами за короткий срок прошли полезные «рабочие университеты».

Практика идейно-воспитательной работы в ВГУ показала, что единственно верный ориентир при этом - не количество прочитанных лекций или число выпускников ФОП, а «конечный продукт» - готовый специалист в единстве его гражданских и профессиональных качеств. Решению этой задачи и подчинена была разнообразная деятельность партийных и комсомольских организаций университета, коллективов кафедр и лабораторий, деканатов. Это позволило добиваться того, что приобретаемые студентами знания не оседали мертвым грузом, а превращались в убеждения, переходя в действие.

Мы провели исследование трудовой и общественно-политической активности молодых специалистов - выпускников Воронежского государственного университета. В поле зрения попали специалисты, работающие на предприятиях города Воронежа и области, имеющие стаж работы после окончания вуза от одного до пяти лет. Всего было опрошено 470 человек.

Исследование показало, что выпускникам ВГУ в целом присуща достаточно высокая трудовая и общественно-политическая активность. Значительная часть молодых специалистов $(87,5 \%)$ уже в первые годы после окончания университета активно повышают свою профессиональную квалификацию. В частности, прошли обучение в аспирантуре - 2,5\% опрошенных, окончили курсы повышения квалификации - 14,3\%, принимали участие в работе научных и научно-практических конференций, семинаров, симпозиумов - 20,4\%, вели подготовку к сдаче кандидатской диссертацией - 2,3\%, самостоятельно изучали специальную литературу - 79,6\%, повышали квалификацию, свой профессиональный уровень в другой форме - 12,5\%. В то же время не повышали свою профессиональную квалификацию - 12,5\%.

Как видно, большинство из этих показателей (самостоятельное изучение литературы по специальности, участие в конкурсах, подготовка к сдаче кандидатского экзамена и т. п.), говорят о высокой ориентированности молодых специалистов на постоянное повышение своего профессионального 
Научные труды Московского гуманитарного университета 2018 № 6

уровня. И это весьма положительный факт, так как именно такой ориентации, желания и умения самостоятельно совершенствовать свои знания, требуют от выпускников высшей школы динамично развивающиеся процессы в системе «наука - производство».

Проявления способности к непрерывной профессиональной мобильности требовало от выпускников высшей школы прежде всего крутая ломка пропорций в профессиональной структуре, сопровождаемая возникновением новых специальностей и специализаций.

Высшая школа не всегда своевременно реагировала тогда на эти изменения, а потому у ее выпускников довольно часто специальность «по диплому» не соответствует специальности, которой им приходится заниматься после окончания вуза. По нашим данным, лишь 59,2\% выпускников ВГУ работало по специальности, записанной в дипломе, остальные - 30,4\% - по родственной (смежной) специальности, а $10,4 \%$ работают по иной специальности.

Коль скоро профессиональная мобильность получила столь широкий размах, очень важно учитывать ее экономические, производственные, а также социальные последствия. Целесообразно, разумеется, чтобы изменение специальности в каждом конкретном случае отвечало, как общественной потребности, например, необходимости заполнения мест занятости во вновь образующихся направлениях и видах промышленного производства, для которых высшая школа пока еще не готовила специалистов, так и субъективной предрасположенности выпускника вуза к изменению своей конкретной профессии. Социальный эффект от изменения специальности значительно больший, когда этот акт совершается свободно, когда он внутренне мотивирован выступает как результат самостоятельно принятого специалистом решения. Это благоприятным образом сказывается как на профессиональном становлении специалиста, так в целом и на развитии производства.

Между тем анализ писем, поступавших в отдел студенческой молодежи ЦК ВЛКСМ от выпускников вузов, содержание проблемных публикаций о распределении и использовании труда молодых специалистов, социологические исследования свидетельствовали о явном неблагополучии в решении этих вопросов. Весьма распространен был вариант начала профессиональной биографии молодого специалиста, когда изменение им полученной в вузе специальности не вызывался ни производственной необходимостью, ни его собственным желанием, а был следствием стечения «случайных» обстоятельств: неоперативности и несогласованности связей отдельных министерств и ведомств с предприятиями и учреждениями, несовершенства планирования выпуска специалистов, недостатков в системе подбора, рас- 
становки и использования кадров на местах. Все это, в конечном счете, отражалось на творческих возможностях молодого специалиста, приводя их к заметному снижению, сковывал его инициативу, самостоятельность, значительно уменьшал эффективность вклада в решение научных и производственных задач. Профессионализм - существенная часть, можно сказать, основа процесса жизненной самореализации молодых специалистов, и от того, как она организована, как протекает, зависит очень многое в их социально- профессиональном становлении.

В проведенном нами исследовании установлено, что там, где молодым специалистам уделялось постоянное внимание, где их стажировка и включение в самостоятельную деятельность осуществлялась при непосредственно помощи наставников, где действовала четкая система продвижения, дающая специалистам осознание перспектив профессионального роста, - там скорее у молодых возникало чувство удовлетворенности своей работой, становилась выше их производственная и общественная активность, ярче проявлялась у них чувство профессионального патриотизма. Среди опрошенных нами специалистов были полностью удовлетворены своей работой, своим положением в трудовом коллективе - 52,0\%, в основном удовлетворены - 8,5\%. Наибольший процент неудовлетворенных среди тех, кто только что приступил к работе. Именно эта категория молодых специалистов - со стажем работы не менее года - обнаружила желание сменить место работы. С повышением стажа работы их число снижалось.

В качестве причин неудовлетворенности своим положением в трудовом коллективе и работой молодые специалисты назвали: неполное использование знаний - 32,8\%, работа не по специальности - 17,6\%, низкая зарплата - 23,3\%, отсутствие перспективы получить квартиру - 10,5\%, просто неинтересная работа - 10,2\%, плохие отношения с руководством - 5,6\%.

Действие этих факторов привело к тому, что уже в течение первого года часть молодых специалистов (9,8\%) меняла место работы. Более активная смена места работы наблюдалось у тех, кто отработал 3 года после окончания вуза. Лишь 60\%специалистов по окончании обусловленного законодательством срока работы оставались по месту распределения. Закрепляемость молодых специалистов, сокращение текучести среди них во многом зависело от эффективной деятельности комитетов комсомола по их трудоустройству и использованию. Внимательное отношение к запросам и интересам молодых специалистов, своевременное оказание им помощи, активное вовлечение в общественную жизнь коллективов - вот наиболее эффективный путь работы с начинающими.

У 78,5\% молодых специалистов активное выполнение общественной работы совпадало со стремлением к постоянному повышению своего идей- 
Научные труды Московского гуманитарного университета 2018 № 6

но-теоретического уровня, с желанием повысить свои знания по общественно-политической проблематике. Для этого ими широко использовались различные формы политической учебы. Например, в системе партийного образования занимались $-12,1 \%$ опрошенных, в системе комсомольского политпросвещения $-44,7 \%$, в системе экономического образования $22,6 \%$, в вечернем университете марксизма-ленинизма $-7,2 \%$.

Наиболее важным показателем, свидетельствующем об активном отношении выпускников ВГУ к повышению своего идейно-теоретического уровня, расширению политического кругозора, являлось, на наш взгляд, самостоятельное изучение молодыми специалистами общественных наук. Почти каждый второй $(44,3 \%)$ выпускник университета самостоятельно продолжал изучать одну-две, а в отдельных случаях, три-четыре общественные дисциплины. Такой всплеск познавательной активности, конечно же, объяснялся, прежде всего, тем, что новые социально-профессиональные позиции выпускников вузов настоятельно требовали от них достаточного высокого уровня общественно-политических знаний, которых, увы, часто не оказывалось в вузовском багаже молодого специалиста. Вот и приходилось срочно наверстывать упущенное. Около 40\% опрошенных нами выпускников заявили, что испытывают недостаток знаний и навыков в области общественно-политической практики. Жизненная необходимость способствовала переоценке значимости этой стороны в подготовке специалиста и формированию у молодых людей уже более практического интереса к общественно-политическому образованию. Уже за стенами вуза некоторая недооценка значения изучения дисциплин общественного цикла, наблюдаемая особенно у студентов инженерных и естественных факультетов, уступали место чувству дефицита знаний и навыков, стремлению как можно скорее восполнить его. Среди проблем, которые более всего интересовали молодых специалистов, на первом месте стояли политические проблемы $61,3 \%$, на втором - проблемы литературы и искусства (51,5\%), на третьем - проблемы семьи, воспитания детей $(25,7 \%)$.

Данные нашего исследования показали, что уровень общественно-политической активности молодых специалистов во многом был определен степенью сформированности их интереса к общественно-политической проблематике и приобретением необходимых навыков еще в годы студенчества. Прослеживалась очень тесная связь между, например, средней оценкой по общественным дисциплинам в дипломе специалиста и актуальным участием его в различных формах общественной работы. Чем выше оценка - тем выше уровень участия, тем более значимы выполняемые им виды общественной деятельности.

Несомненно, говоря о степени использования молодыми специалиста- 
ми, полученных в вузе знаний и навыков, мы должны были учитывать, что актуальные условия проявления общественно-политической активности выпускников могут быть различными. Реализация знаний и умений зависит от уровня идейно-воспитательной работы в трудовых коллективах, сложившегося в нем морально-психологического климата, традиций. Однако это не снимало в целом проблемы более качественной подготовки специалистов в вузах. Оценивая уровень полученной ими в университете подготовки в соотношении с теми задачами, которые приходится решать на практике, молодые специалисты высказали полную удовлетворенность всеми сторонами своей подготовки в 24,4\% случаев, в целом удовлетворены, но ощущали недостаток навыков лекционно-пропагандистской работы - 7\%, навыков лекционно-пропагандистской работы - 7\%, недостаток профессиональных (по специальности) знаний и умений - 26\%, затруднились пока что определить свое отношение - 11\% опрошенных.

Как видно, наиболее часто встречаемые молодыми специалистами трудности связаны с их неподготовленностью к организаторской, идейно-воспитательной работе в трудовых коллективах. Данная проблема обозначилась уже сравнительно давно и не случайно XIX съезд ВЛКСМ снова обратил внимание комитетов комсомола высших учебных заведений на необходимость постоянного повышения эффективности всех имеющихся форм воспитания общественно-политической, социальной активности будущих специалистов, подготовки их к активной агитационно-пропагандистской, культурно-массовой, организаторской и воспитательной работе в трудовых коллективах, школах, ГПту и по месту жительства.

Конечно, это непросто - возглавить на общественных началах школу молодого лектора, самодеятельный кружок, спортивную секцию. Необходимы широкие знания, организаторские навыки. Приобрести их будущему специалисту помогала общественно-политическая практика. Там, где она была организована и проводилась на высоком уровне - результаты были налицо.

В дополнение к анкетному опросу выпускников мы провели опрос экспертов, в качестве которых выступили непосредственные начальники и секретари партийных или комсомольских организаций по месту работы молодых специалистов.

Более чем у двух третей молодых специалистов наличие таких важных качеств, как творческое отношение к профессии, инициативное, неравнодушное отношение к работе и стремление к профессиональному совершенствованию, оценено экспертами «высоко» и «достаточно высоко». Однако обращает внимание то, что более пятой части специалистов затруднились дать однозначную оценку. В основном это касалось начинающих работни- 
Научные труды Московского гуманитарного университета 2018 № 6

ков, которые еще не успели раскрыться, не проявили себя достаточно определенно. Были и такие специалисты, которые, по мнению экспертов, обнаружили недостаточную степень наличия у них оцениваемых качеств либо их полное отсутствие.

В целом анализ результатов конкретно-социологического исследования трудовой и общественно-политической активности выпускников ВГУ позволил оценить сложившуюся в данном вузе систему социально-профессиональной подготовки специалистов как достаточно эффективную. Абсолютное большинство выпускников успешно включалось в производственную и общественно-политическую жизнь трудовых коллективов, сравнительно быстро адаптировалось к новым условиям. Все это есть результат огромного труда коллектива профессоров и преподавателей университета, его общественных организаций — их неустанного поиска новых форм воспитания будущих специалистов. Необходимы были широкие знания, организаторские навыки.

Конечно, это непросто - возглавить на общественных началах школу молодого лектора, самодеятельный кружок, спортивную секцию. Необходимы широкие знания, организаторские навыки. Приобрести их будущему специалисту помогает общественно-политическая практика.

Там, где она организована и проводится на высоком уровне - результаты налицо. Молодые специалисты быстро адаптировались к новым условиям в трудовом коллективе, отличались активной жизненной позицией.

Так, благодаря комсомолу и дружбе с социологией, ваш покорный слуга на всю оставшуюся жизнь приобрел квалификацию социолога.

Дата поступления: 30.08.2018 г.

Карпухин Олег Иванович - доктор социологических наук, профессор главный научный сотрудник Центра социологии культуры и информационной политики, профессор кафедры философии, культурологии и политологии Московского гуманитарного университета, Заслуженный деятель науки РФ. Адрес: 111395, Россия, г. Москва, ул. Юности, д. 5, корп. 6. Тел.: +7 (499) 374-75-95. Эл. адрес: ifpi@mosgu.ru

Karpukhin Oleg Ivanovich, Doctor of Sociology, Professor, Leading Research Fellow, Centre for Sociology of Culture and Information Politics; Professor, Department of Philosophy, Culture Studies and Political Studies, Moscow University for the Humanities; Honoured Scientist of the Russian Federation. Postal address: 5, Bldg. 6, Yunosti St., Moscow, Russian Federation, 111395. Tel.: + 7 (499) 374-7595. E-mail: ifpi@mosgu.ru 


\section{Для цитирования:}

Карпухин О. И. Студент сегодня - специалист завтра (к вопросу об эффективности идейно-воспитательной работы комсомола в вузе) [Электронный ресурс] // Научные труды Московского гуманитарного университета. 2018. № 6. URL: http://journals.mosgu.ru/trudy/article/view/835 (дата обращения: дд.мм.гг.). DOI: 10.17805/trudy.2018.6.4 